\title{
Use of dairies by postreproductive flocks of European starlings
}

\author{
H. J. Homan, ${ }^{* 1}$ J. T. LeJeune,† D. L. Pearl,‡ T. W. Seamans,\# A. A. Slowik, ${ }^{*}$ Mark R. Morasch,† and G. M. Linz ${ }^{*}$ \\ *USDA, Animal Plant Health Inspection Service, Wildlife Services, National Wildlife Research Center, Bismarck, ND 58501 \\ †Food Animal Health Research Program, Ohio Agricultural Research and Development Center, The Ohio State University, Wooster 44691 \\ $\ddagger$ Department of Population Medicine, Ontario Veterinary College, University of Guelph, Guelph, Ontario N1G 2W1, Canada \\ \#USDA, Animal Plant Health Inspection Service, Wildlife Services, National Wildlife Research Center, Sandusky, OH 44870
}

\begin{abstract}
Knowledge of the behavior and movement patterns of European starlings (Sturnus vulgaris L.) is important to wildlife managers that seek to resolve conflicts at livestock facilities. We captured and radio tagged 10 starlings at each of 5 dairies in northeastern Ohio. From September 19 to October 31, 2007, we obtained sufficient data from 40 birds to study their behavior and movements. The birds visited the dairies where they were initially captured (home sites) on $85 \%$ of the days, spending $58 \%$ of each day at the dairies. Onsite arrival and departure times were $2.5 \mathrm{~h}$ after sunrise and $3.1 \mathrm{~h}$ before sunset. Daily visits by radio-tagged cohorts from the other dairies were greatest for the 2 most proximate dairies (1.3 $\mathrm{km}$ apart), with number of visits between this pairing $>7 \times$ that of the 9 other pairings combined (4.1-6.5 km apart). Two birds used their home sites intermittently as roosts, arriving 3.8 $\mathrm{h}$ before sunset and departing $0.2 \mathrm{~h}$ after sunrise. In addition to using home-site roosts, these birds also used a distant roost $(22 \mathrm{~km})$ that was used by 36 of the 40 birds. The efficacy of starling management programs, especially lethal management, depends on degree of site fidelity, use of other facilities, and roosting behavior. For example, starlings that use dairies as roosting sites may require a different management strategy than required at dairies used as daytime sites because of differences in arrival and departure behavior. Our research will help resource managers evaluate current management strategies already in place and change them, if needed, to fit the behavior profile of starlings using dairies and other types of livestock facilities.
\end{abstract}

Key words: behavior, dairy, radio telemetry, starling

\section{INTRODUCTION}

Complaints about European starlings (Sturnus vulgaris L.) occur most often during fall and winter, when

Received February 19, 2013.

Accepted April 9, 2013.

${ }^{1}$ Corresponding author: jeffrey.h.homan@aphis.usda.gov flocks of thousands amass at livestock facilities to eat, loaf in barns, and drink and bathe in watering troughs. The economic effects of starlings include losses from consumption and spoilage of feed stocks, deterioration of feed nutrient quality through selective foraging, and corrosion of facility infrastructure from acidic excreta (Besser et al., 1968; Bernardi et al., 2009; Depenbusch et al., 2011). Starlings cost Pennsylvania dairy producers about $\$ 10$ million annually in feed losses (Shwiff et al., 2012). However, starlings also asymptomatically carry bacterial pathogens, including Salmonella enterica and several Escherichia coli serotypes, harmful to both livestock and humans (Pedersen and Clark, 2007; Gaukler et al., 2009; Carlson et al., 2011; Cernicchiaro et al., 2012). The added veterinary costs incurred from starlings transmitting and amplifying bacterial pathogens probably exceed the economic losses from consumption of feed. Veterinary costs at Pennsylvania dairies with 1,000 to 10,000 starlings were $38 \%$ higher ( $\$ 91 \mathrm{cow} / \mathrm{yr}$ ) than at dairies with no starlings (\$66); when veterinary costs were analyzed in a simple main-effects ANOVA, presence of starlings had a highly significant effect (Shwiff et al., 2012).

During the fall of 2007, we captured 50 starlings at dairies in northeastern Ohio and used radio telemetry to monitor use of dairy sites and daily movements. Our goals were to gather baseline behavioral data and describe, given that starlings are potential vectors of disease, the epidemiological implications of their presence at dairies. We collected data on daily use, visitation rates to neighboring dairies, and roost-site behavior. These data are important to resource managers as well as epidemiologists and can provide valuable insight for those managing large or persistent starling infestations, which often require the use of the avicide DRC-1339 (3-chloro-4-methylaniline hydrochloride; Homan et al., 2010a).

\section{MATERIALS AND METHODS}

We visited dairies in Wayne and Holmes counties in northeastern Ohio. We selected 5 dairies near Sterling, Ohio $\left(40.967^{\circ} \mathrm{N}, 81.848^{\circ} \mathrm{W}\right)$, in rural Wayne County 


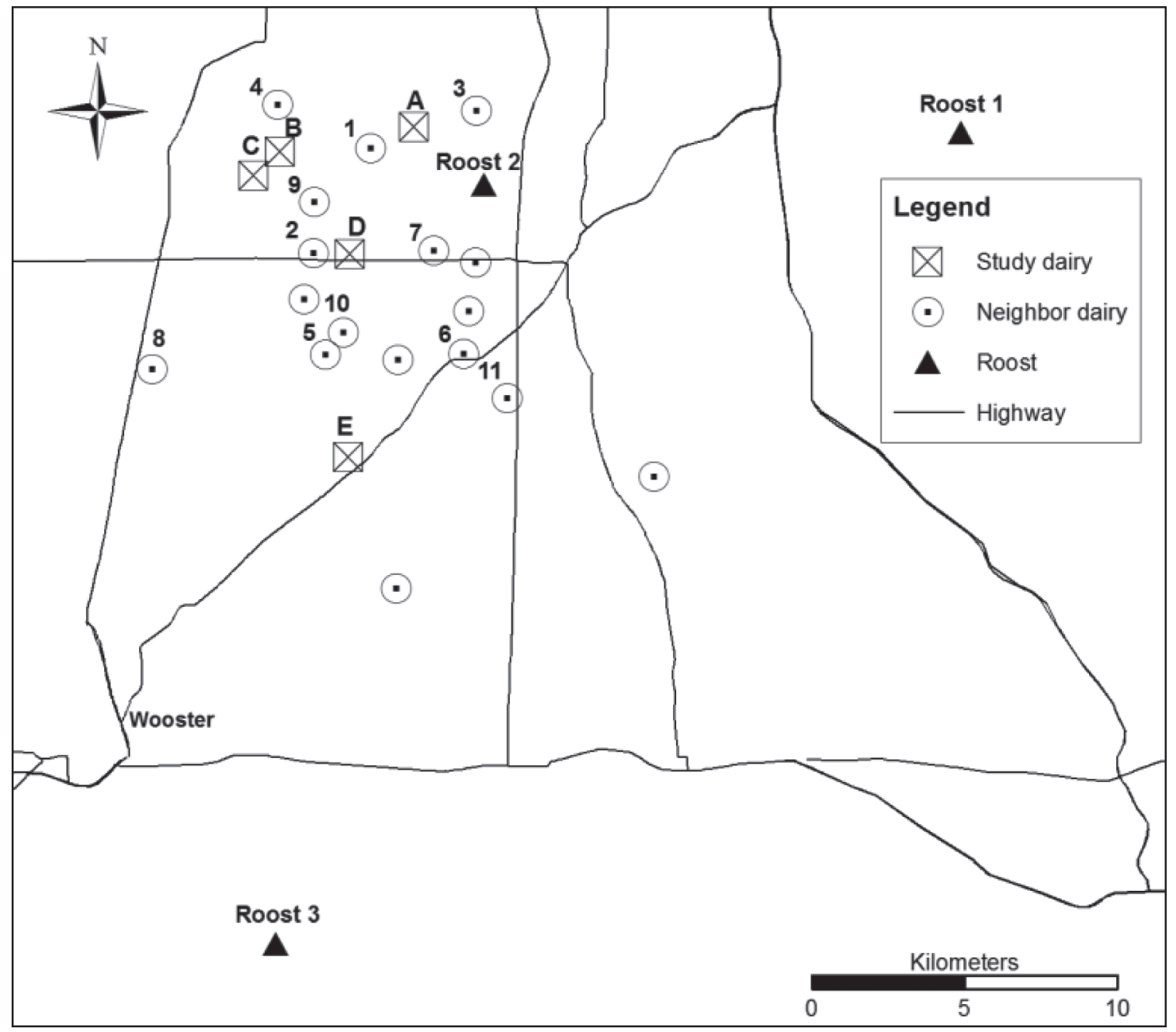

Figure 1. Locations of 5 study dairies (A-E), neighboring dairies (1-11), and roosts (1-3) used by 40 radio-tagged European starlings tracked in northeastern Ohio during September and October 2007. Six neighboring dairies that were monitored but not used are not numbered. The neighboring dairies were ranked first by number of radio-tagged birds attending [maximum 10 (1), minimum 1 (8-11)] followed by number of days visited [maximum 23 (2), minimum 1 (11)].

$\left(1,400 \mathrm{~km}^{2}\right)$. Habitat composition of the county was $60 \%$ crop, $12 \%$ pasture, $22 \%$ forest, $5 \%$ urban, and $1 \%$ other. Over 400 dairies were in the county, with the preponderance holding $\leq 200$ head (Clark et al., 2008; NASS, 2012). Wayne County ranked second among Ohio counties in number of dairies. We conducted the research during September and October, the seasonal peak for pathogen prevalence at dairies in northeastern Ohio (Wetzel and LeJeune, 2006). The 5 small-sized dairies (A-E) were an average of $5 \mathrm{~km}$ apart, ranging from 1.3 to $11.0 \mathrm{~km}$ in distance (Figure 1). These dairies were chosen because of their proximity to one another and their consistency of use by starlings numbering $\geq 1,000$. We used this design to provide a reasonable chance for exchange of radio-tagged cohorts among the dairies.
We radio tagged 10 starlings at each dairy; however, 1 transmitter malfunctioned and therefore only 49 birds were radio tagged. We captured the starlings from September 17 to 24, spending $\leq 2 \mathrm{~d}$ at each dairy. We captured birds with mist nets at barn openings. We used external characteristics for identifying age and sex (Kessel, 1951; Smith et al., 2005). We attached the radio transmitter (model ANTC-M4-2L, Lotek Wireless Inc., Ontario, Canada) with an elastic loop harness that positioned the transmitter over the anterior portion of the bird's back (Rappole and Tipton, 1991). Total mass of radio and harness was $2.4 \mathrm{~g}$. To meet the criterion that the radio unit be $\leq 3 \%$ of body mass, we used only adult birds weighing $\geq 80 \mathrm{~g}$. We released the starlings at the capture site immediately after tagging. We allowed a 2-d acclimation period following the day 
of tagging to give the radio-tagged birds time to adjust to the transmitter.

We installed stationary receiving systems at the study dairies from September 19 to 22. The systems were placed in panoramic locations away from buildings and other objects that could dampen or block radio signals. Each receiving system consisted of a Lotek SRX600 data-logging receiver (Lotek Wireless Inc.) cabled to a 6 -element yagi antenna bolted to a $2.4-\mathrm{m}(5-\times 5-\mathrm{cm})$ wooden pole that was elevated on a stanchion. The receiver was kept in a weather-proof container. All receivers were time and date synchronized before deployment. The data loggers scanned through the 49 radio codes every $30 \mathrm{~s}$. For each signal pulse received, the following data were logged into the receiver's internal memory: radio frequency, date, time, and signal strength (maximum 255). We downloaded the data onsite every $4 \mathrm{~d}$ until the end of the study, October 31 . The line-of-sight receiving range of the stationary systems was $\leq 0.5 \mathrm{~km}$.

We used two 4-wheel-drive pickup trucks for mobile receiving systems. The mobile systems consisted of SRX600 data loggers cabled to dual, rotatable, 6-element, yagi antennas. The data loggers had GPS that recorded the decimal degree coordinates of the mobile unit when a radio signal was received. The line-of-sight range of the mobile receiving system was $\leq 1 \mathrm{~km}$. The mobile units were used to ensure that birds not consistently using the dairies were still present during the study period, which occurred during fall migration. The study area was a $50-\mathrm{km}$ radius encompassing the dairies. The mobile units conducted searches both day and night, operating between 6 to $12 \mathrm{~h} / \mathrm{d}$ and 5 to 7 $\mathrm{d} /$ wk. The study area was quartered and each mobile unit searched all habitats (e.g., suburbs, towns, parks, landfills) within its assigned 2 quarters. Assignments were alternated weekly.

We used 5 movable receiving systems to monitor 17 neighboring dairies (neighbor sites), ranging from 1.1 to $16.4 \mathrm{~km}$ from the 5 study dairies (Figure 1). The movable systems were setup and operated in the same manner as the systems used at the study dairies. The receiving systems operated from September 21 to October 31 and were moved every 7 to $10 \mathrm{~d}$. We relocated the systems to other dairies based on our observations of starling flocks onsite, detections of radio-tagged birds by mobile units, or dairy locations in respect to roost flightlines. We used one of the movable systems to monitor a roost from October 2 to 8 .

We included all birds having $\geq 1$ valid radio fix in the analyses. A fix was valid if $\geq 5$ signal pulses were logged over a 15-min scanning period starting with the reception of the first signal. Signal strength had to average $\geq 100$ or attain $\geq 200$ at least once over the 15 -min period. The fixes could be taken anytime and anywhere in the study area. We calculated the number of days a bird was in the study area by subtracting the end date of the 2-d acclimation period from the date the last fix was made. The maximum number of days on which data were collected at the 5 study dairies ranged between 35 and 42 , depending on the staggered entry dates for the birds. For example, a bird captured on September 17 with its last fix on October 31 would be credited with being in the study area $42 \mathrm{~d}$. Neither the number of fixes nor the number of days intervening between consecutive fixes was used as criteria.

We collected the following variables: (1) daily visits to the 5 study dairies and hours spent at the location per day, (2) daily visits to the 17 neighboring dairies and hours spent per day, (3) arrival and departure times at dairy roosts, and (4) arrival and departure times at a major roost site over an 8 -d period. We calculated site fidelity by categorizing the study dairy where the bird was captured as its home site. One or more fixes recorded at the home site over a diurnal $24-\mathrm{h}$ period was tabulated as a daily visit. Site fidelity was calculated by dividing the number of daily visits to the home site by the total days the bird was in the study area. Diurnal visits made to each home site's respective set of 4 confederate study dairies were categorized as away visits. We compared use among the 20 unique home-away pairs by summing the number of away visits for each pairing (e.g., AB, BA) and dividing it by the total number of away visits for all pairings.

Hourly use of study dairies was measured as the number of 1-h segments between 0900 and $1700 \mathrm{~h}$ that a bird's radio signal was fixed at any of the 5 study dairies, independent of the birds' home-site affiliations. For example, a bird that spent four 1-h segments at its home site and four 1-h segments at one of its away sites would be credited with spending the entire day at the study dairies. We used the 0900 to $1700 \mathrm{~h}$ timeframe because the majority of birds would not consistently start using the study dairies before $0900 \mathrm{~h}$ and would usually depart from the dairies between 1600 and 1700 $\mathrm{h}$. The criteria for determining validity of hourly radio fixes were the same as those used for determining validity of daily radio fixes.

We used Visual Basic for Applications with Excel (Microsoft Corp., Redmond, WA) to extract valid fixes and summarize hourly and daily use. Because most data sets were skewed, we used median $\left(\mu_{1 / 2}\right)$ and interquartile range (IQR) to describe average and variance. Site fidelity, visits to away and neighbor sites, and hourly use of dairies were reported as percentages. We used Pearson product-moment correlation to assess the effect of distance from home site on visitation rates at away sites and neighbor sites. We calculated the visitation rate of each radio-tagged cohort by dividing the 
total number of daily visits that occurred during the span of days the receiving system was active by the total number of visits that would have accrued if all cohort members present in the study area had made daily visits. Away and neighbor sites not visited were not included in the analysis. We used the Wald-Wolfowitz runs test to assess randomness of missing hourly segments. We used Wilcoxon-Mann-Whitney tests to assess statistical differences between males and females in site fidelity, hourly use, arrival and departure times at study dairies, and number of daily visits to away and neighbor sites. Statistical significance was accepted at $\alpha<0.10$.

\section{RESULTS}

We obtained sufficient data from 40 (15 females, 25 males) of the 49 radio-tagged birds to conduct a meaningful analysis. We did not detect differences in variables between sexes $(P=0.20-0.64)$, and sexes were pooled. The first day of data collection was September 20; the last day that all 40 birds were present in the study area was September 27. At the study's midpoint (October 10), 32 birds were present. During the final week, 23 birds were present on average, with 19 fixed by $\geq 1$ receivers on October 31 . Two birds never used their home sites, and 3 others temporarily stopped using their home sites after being tagged. Of these, 4 developed new allegiances at 3 neighbor sites $(6,9,10$; Figure 1) that were from 2 to $8 \mathrm{~km}$ from their home sites (A, C, D). During mid to late October, 3 of the 4 expatriates made sporadic daily visits ( $\mathrm{n}=8$ visits) back to their home sites (C, D).

The receiving systems at the 5 study dairies operated for a cumulative $208 \mathrm{~d}$, recording 1,055 daily visits. Home and away categories were 802 and 253 visits, respectively. Site fidelity averaged $85 \%(\mathrm{n}=40$; IQR $=$ 64 ; range $=0-100)$, with 21 birds $\geq 80 \%$ and 11 having $100 \%$. The birds spent $58 \%(\mathrm{n}=40$; IQR $=36$; range $=0-97)$ of the day at the study dairies, with arrival and departure times $2.5 \mathrm{~h}(\mathrm{n}=36$; IQR $=1.5$; range $=0.05-3.63)$ after sunrise and $3.1 \mathrm{~h}(\mathrm{n}=36$; IQR $=$ 1.6 ; range $=5.4-1.2$ ) before sunset. The missing hourly segments occurred randomly over the 8 -h period $(P=$ $0.40)$. Our observations using the mobile telemetry systems suggest that many of the missing hourly segments were either from offsite forays for berries and invertebrates in adjoining habitats (e.g., pastures, residential lawns, transportation easements) or from blocked radio signals during extended stays in onsite barns (e.g., loafing, sun shelter).

Of the 20 home-away pairs, 11 had $\geq 1$ daily visits. Site $\mathrm{E}$ was not visited by any confederate cohort. The pairing involving the 2 closest study dairies $(1.3 \mathrm{~km}$;
B-C) accounted for 88\% [98 (B-C) and $124(\mathrm{C}-\mathrm{B})]$ of the 253 away visits. None of the remaining 9 pairs, which ranged from 4.1 to $6.5 \mathrm{~km}$ from home sites, had visits $>3 \%$ of total away visits. We recorded daily visits at 11 of the 17 neighbor sites. The receiving systems at the 11 sites operated for a cumulative $85 \mathrm{~d}$ and recorded 110 visits. Of the 55 home-neighbor pairs, 19 had $\geq 1$ daily visits. The 3 most heavily used neighbor sites ranged from 1.1 to $11.9 \mathrm{~km}$ from the visitors' home sites $\left(\mathrm{n}=20 ; \mu_{1 / 2}=3 \mathrm{~km}\right.$; IQR $\left.=3\right)$, accounted for 17 of the total 27 visiting birds, and contributed $42 \%$ (46) of the 110 visits (1, 2, 3; Figure 1$)$. Two of the 3 sites $(1,3)$, including the most distant one $(11.9 \mathrm{~km})$, were on a flightline leading to 2 roosts. Of the 27 birds that visited neighbor sites, 3 contributed $44 \%$ (49) of the visits, with 1 bird (Site D) accounting for the majority ( $\mathrm{n}=30$ ) of those visits. On average, the birds using neighbor sites spent $25 \%$ of their day at that location $(\mathrm{n}=27, \mathrm{IQR}=37$, range: $12-100)$.

Only 10 of the 105 home-away and home-neighbor pairs were $\leq 2.5 \mathrm{~km}$ from home sites, but $75 \%$ of the 363 daily visits made to away sites and neighbor sites were $\leq 2.5 \mathrm{~km}$ from home sites. Visitation rates to the 19 home-neighbor pairs and the 11 home-away pairs were negatively correlated with distance from home sites $\left(r_{30}\right.$ $=-0.56 ; P=0.001 ;$ Figure 2).

Two birds used their home sites as roosts (sites C, D), using them for 8 and 13 nights during late September and mid-October, respectively. Except for 1 missed night by the latter bird, home-site roosting occurred on consecutive nights. Average arrival and departure times for birds using home-site roosts were $3.8 \mathrm{~h}$ ( $\mathrm{IQR}=6.8$; range $=0.7-9.2)$ before sunset and $0.2 \mathrm{~h}(\mathrm{IQR}=0.6$;

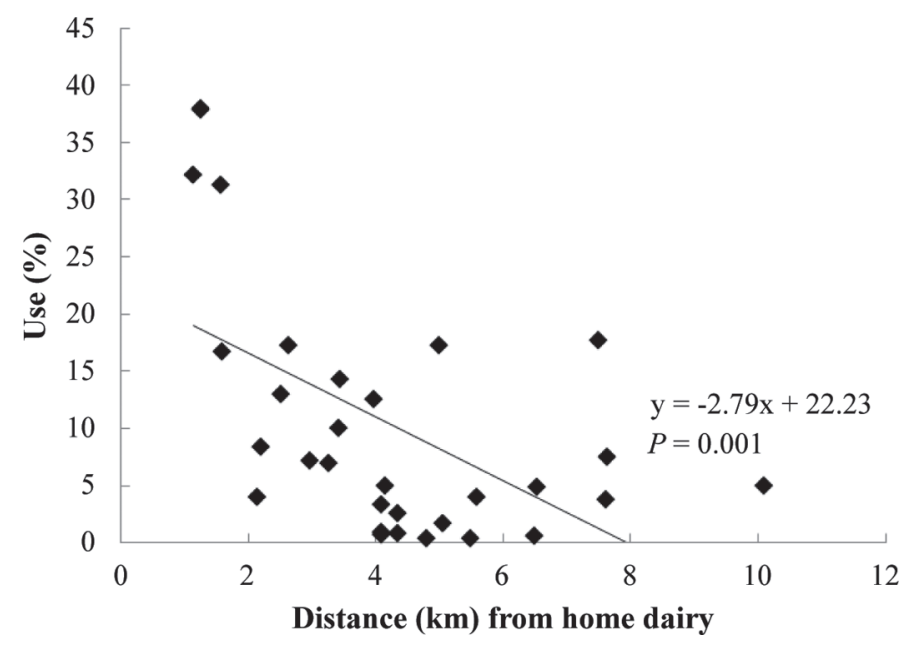

Figure 2. Inverse relationship between distance $(\mathrm{km})$ from 5 study dairies in northeastern Ohio and number of diurnal visits (percentage of use) made to dairies by 5 cohorts of radio-tagged European starlings during September and October 2007. 
range $=0.0-4.5)$ after sunrise. In addition to using the home sites for roosts, these birds also used a roost about $22 \mathrm{~km}$ away in a large (100 ha) wetland embedded in a wooded complex of industrial sites and suburban developments near Akron, Ohio (Roost 1, Figure 1). The birds roosted in phragmites (Phragmites spp.); this was a major roost used by 36 of the 40 radio-tagged birds. In early October, 19 birds used this roost for a cumulative 118 nights over a 7 -night monitoring period $\left(\mu_{1 / 2}=\right.$ 7 nights; IQR = 1); 12 of the 19 birds used the roost on every night. Average arrival and departure times were $0.30 \mathrm{~h}(\mathrm{IQR}=6.8$; range $=0.7-9.2)$ before sunset and $0.2 \mathrm{~h}(\mathrm{IQR}=6.8$; range $=0.7-9.2)$ before sunrise. A smaller satellite roost (also a wetland, roost 2 ) was used by 17 birds, of which 15 also used the major roost at some point during the study period. The satellite roost was $15 \mathrm{~km}$ closer to the study dairies. One bird occasionally used a woodlot roost $15 \mathrm{~km}$ south of its home site (roost 3) and $33 \mathrm{~km}$ southwest of the major roost, which the bird also attended. Although the roosting populations were not counted, our visual estimates indicated that the populations of the major roost and woodlot roost exceeded 100,000, with the woodlot roost consisting mostly of young-of-the-year birds. Last, 2 birds roosted at a neighbor site (10; Figure 1 ) that was 6 and $3 \mathrm{~km}$ from the birds' respective home sites (B, D). One of these birds also used roost 1 .

\section{DISCUSSION}

Despite using a large communal roost over $20 \mathrm{~km}$ away, the majority of birds from the study dairies spent their days either at or near their sites of initial capture. The fidelity to specific dairies occurred even though the birds were in a study area that averaged 1 dairy per $3.5 \mathrm{~km}^{2}$. The extent of site fidelity went to the smallest spatial scale of the study, where 6 birds $(33 \%)$ from the closest pairing of study dairies did not use their respective away sites less than $2 \mathrm{~km}$ away. In comparison, starlings captured and radio tagged at several feedlots in Kansas and Texas during winter showed varying levels of daily site fidelity, ranging from 54 to $95 \%$ (Homan et al., 2010b; Gaukler et al., 2012). The authors attributed this variability to the composition of the habitats surrounding the feedlots. Compared with isolated feedlots, site fidelity was lower at feedlots located near towns or near other livestock-dedicated operations. The Great Plains landscape overall was lacking in habitats preferred by starlings and feedlots occurred at low densities, thus site fidelity in these studies was expected.

The study area in Ohio, however, was replete with habitats preferred by starlings (e.g., towns, pastures and fields, parks, landfills) and had a large group of dairies of similar sizes and management practices. The diverse habitat composition of the landscape had no apparent effect on site fidelity. The phenomenon of site fidelity by postreproductive starlings is not restricted to livestock facilities in rural environments, but has also been documented in urban and suburban environments (Caccamise, 1991). The generalness of this behavior thus implies that it may have a positive influence on survival rates. For example, site fidelity creates a familiarity with an area perhaps leading to improved foraging efficiency and an increased awareness of predator haunts (Tinbergen, 1981; Caccamise and Morrison, 1986); moreover, by not wandering about, a bird can reduce its flight time, which increases energy efficiency and reduces exposure to aerial predation.

The first step in managing a conflict with starlings at dairies and other livestock facilities is estimating the size and scope of the problem. Strong site fidelity presents a less challenging management scenario. The corollary of site fidelity is low population turnover, which, besides reducing the scope of the problem, allows for more accurate population estimates compared with facilities having high population turnover. With high population turnover, the effective population size is generally underestimated because the population, though appearing to be stable, is constantly being refreshed by new birds moving among various sites (Caccamise, 1990; Bibby et al., 2000). Our research on starlings conducted over several telemetry studies that were done in different environments and seasons suggests starlings have a behavioral tendency toward site fidelity. A successful management program using lethal methods (e.g., DRC-1339) should thus remove nearly all starlings from a treated facility. The causes of unsuccessful or apparently unsuccessful attempts at population management may be from undercounting, bait aversion, short-livedness of DRC-1339, or high population turnover (Darden and Schwab, 1970; Caccamise, 1990; Feare, 2010). We speculate that high population turnover would be rare unless other facilities harboring large populations of starlings were nearby. To prevent a rapid repopulating of a treated facility, we would recommend concurrent management of all starling-infested sites within a couple of kilometers of the treated facility.

The vast majority of radio-tagged birds in the Ohio study only used dairies as foci for their daily activities, departing by late afternoon. When the study dairies were used intermittently as roost sites, they were not used for daily activities, especially morning activities. However, this behavior seems more plastic than site fidelity behavior. Onsite roosting accompanied with consistent daytime use does occur at livestock facilities (Homan et al., 2012). Usually DRC-1339 baiting operations are conducted during the morning, but our 
data from the Ohio study indicate that some flexibility in timing may be required. If management is focused solely on roosting starlings, and previous attempts at management were unsuccessful, employing an earlyafternoon strategy might increase success. Regardless of the timing of baitings with DRC-1339, wildlife managers should be aware that, despite being in rural areas during the daytime, starlings may use roosts near or within population centers (Homan et al., 2006). Because DRC-1339 is a slow-acting toxin, this can lead to the public encountering sick, dying, and dead birds (Homan et al., 2012).

Finally, from an epidemiological perspective, our research has provided an ecological rationale (i.e., strong site fidelity) for the oft-observed phenomenon at Ohio dairies during early fall of spatial clustering of identical, genetic subtypes of pathogenic bacteria (e.g., E. coli O157:H7; Wetzel and LeJeune, 2006). The fidelity behavior we observed both at daily levels and within-day levels should constrain the exposure time and reduce the chances of starlings acquiring novel, offsite pathogens. Reduced exposure, in turn, may contribute to spatially isolated instances of indistinguishable genetic subtypes.

\section{ACKNOWLEDGMENTS}

We thank the following for their support and assistance with our project: R. Beason, J. Bourassa, N. Bower, C. Peery, C. Kauffman, J. Kauffman, R. Kauffman, and L. Penry of the National Wildlife Research Center; N. Bower and M. van den Tillart of Lotek Wireless Inc.; C. Peery, University of Idaho, Boise; R. Kauffman, Ohio Agricultural Research and Development Center, Wooster; and C. and J. Kauffman, volunteers, Shreve, OH. The research was supported, in part, by the USDA Cooperative State Research, Education and Extension Service, Epidemiological Approaches to Food Safety Program of the National Research Initiative (Grant number 2006-35212-17039), Washington, DC. Animal care and use procedures were followed in accordance with USDA Wildlife Services' National Wildlife Research Center IACUC guidelines (NWRC Study Protocol QA-1464, Study Director: H. J. Homan). Use of commercial products does not constitute an endorsement.

\section{REFERENCES}

Bernardi, E., D. J. Bowden, P. Brimblecombe, H. Kenneally, and L. Morselli. 2009. The effect of uric acid on outdoor copper and bronze. Sci. Total Environ. 407:2383-2389. http://dx.doi. org/10.1016/j.scitotenv.2008.12.014.
Besser, J. F., J. W. DeGrazio, and J. L. Guarino. 1968. Costs of wintering starlings and red-winged blackbirds at feedlots. J. Wildl. Manage. 32:179-180. http://dx.doi.org/10.2307/3798253.

Bibby, C. J., N. D. Burgess, D. A. Hill, and S. Mustoe. 2000. Bird Census Techniques. 2nd ed. Academic Press, London, UK.

Caccamise, D. F. 1990. Communal starling roosts: Implications for control. Pages 332-338 in Proc. 14th Vertebr. Pest Conf., Sacramento, CA. University of California, Davis.

Caccamise, D. F. 1991. European starling fidelity to diurnal activity centers: Role of foraging substrate quality. Wilson Bull. 103:1224.

Caccamise, D. F., and D. W. Morrison. 1986. Avian communal roosting: Implications of "diurnal activity centers." Am. Nat. 128:191198. http://dx.doi.org/10.1086/284553.

Carlson, J. C., A. B. Franklin, D. R. Hyatt, S. E. Petit, and G. M. Linz. 2011. The role of starlings in the spread of Salmonella within concentrated animal feeding operations. J. Appl. Ecol. 48:479486. http://dx.doi.org/10.1111/j.1365-2664.2010.01935.x.

Cernicchiaro, N., D. L. Pearl, S. A. McEwen, L. Harpster, H. J. Homan, G. M. Linz, and J. T. LeJeune. 2012. Association of wild bird density and farm management factors with the prevalence of $E$. coli O157 in dairy herds in Ohio (2007-2009). Zoonoses Public Health 59:320-329. http://dx.doi.org/10.1111/j.1863-2378.2012.01457.x.

Clark, J., H. Kendall, and W. Flinn. 2008. Ohio dairy industry: The geography and impact of a key sector. Social Responsibility Initiative, Department of Human and Community Development, The Ohio State University. Accessed Feb. 19, 2013. http://aede.osu. edu/sites/drupal-aede.web/files/imce/SRIReport2008.pdf.

Darden, T. R., and R. G. Schwab. 1970. Nonbiological alteration of 3-chloro p-toluidine hydrocholoride (DRC-1339) in an aqueous solution. Bird Control Seminars Proc. Paper 197. Accessed Feb. 19, 2013. http://digitalcommons.unl.edu/icwdmbirdcontrol/197.

Depenbusch, B. E., J. S. Drouillard, and C. D. Lee. 2011. Feed depredation by European starlings in a Kansas feedlot. Human-Wildl. Interact. 5:58-65.

Feare, C. J. 2010. The use of Starlicide ${ }^{\circledR}$ in preliminary trials to control invasive common myna (Acridotheres tristis) populations on St Helena and Ascension Islands, Atlantic Ocean. Conserv. Evidence 7:52-61.

Gaukler, S. M., H. J. Homan, G. M. Linz, and W. J. Bleier. 2012. Using radio-telemetry to assess the risk European starlings pose in pathogen transmission among feedlots. Human-Wildl. Interact. $6: 30-37$.

Gaukler, S. M., G. M. Linz, J. S. Sherwood, N. W. Dyer, W. J. Bleier, Y. M. Wannemuehler, L. K. Nolan, and C. M. Logue. 2009. Escherichia coli, Salmonella, and Mycobacterium avium ssp. paratuberculosis in wild European starlings at a Kansas cattle feedlot. Avian Dis. 53:544-551. http://dx.doi.org/10.1637/8920-050809-Reg.1.

Homan, H. J., G. M. Linz, S. Beckerman, A. G. Duffiney, and T. D Halstead. 2010a. European starling preferences for bait substrates used in DRC-1339 applications. Human-Wildl. Conflicts 4:25-31.

Homan, H. J., G. M. Linz, G. W. Unrein, J. R. Thiele, and J. M. Hobbs. 2006. Movements of European starlings captured at a winter roost in Omaha, Nebraska. Pages 79-82 in 20th Proc. N. Am. Prairie Conf., Kearney, NE. Department of Biology, University of Nebraska, Kearney.

Homan, H. J., A. A. Slowik, L. B. Penry, W. Anderson, and G. M. Linz. 2012. Site use of European starlings wintering in central New Jersey. Pages 230-234 in 25th Proc. Vert. Pest Conf., Monterey, CA. University of California, Davis.

Homan, H. J., A. A. Slowik, L. B. Penry, M. J. Bodenchuk, R. L. Gilliland, and G. M. Linz. 2010b. Site use of European starlings captured and radio-tagged at Texas feedlots during winter. Proc. Vert. Pest Conf. 24:250-256.

Kessel, B. 1951. Criteria for sexing and aging European Starlings (Sturnus vulgaris). Bird-Banding 22:16-23. http://dx.doi org $/ 10.2307 / 4510224$.

NASS (National Agricultural Statistics Service). 2012. Ohio county estimates. Accessed Feb. 19, 2013. http://www.nass.usda.gov/ Statistics_by_State/Ohio/Publications/County_Estimates/2008 cattle.TXT. 
Pedersen, K., and L. Clark. 2007. A review of Shiga toxin Escherichia coli and Salmonella enterica in cattle and free-ranging birds: Potential association and epidemiological links. Human-Wildl. Conflicts 1:68-77.

Rappole, J. H., and A. R. Tipton. 1991. New harness design for attachment of radio transmitters to small passerines. J. Field Ornithol. 62:335-337.

Shwiff, S. A., J. C. Carlson, J. H. Glass, J. Suckow, M. S. Lowney, K. M. Moxcey, B. Larson, and G. M. Linz. 2012. Producer survey of bird-livestock interactions in commercial dairies. J. Dairy Sci. 95:6820-6829. http://dx.doi.org/10.3168/jds.2011-5216.
Smith, E. L., I. C. Cuthill, R. Griffiths, V. J. Greenwood, A. R. Goldsmith, and J. E. Evans. 2005. Sexing starlings, Sturnus vulgaris, using iris colour. Ringing Migr. 22:193-197. http://dx.doi. org $/ 10.1080 / 03078698.2005 .9674332$.

Tinbergen, J. M. 1981. Foraging decisions in starlings (Sturnus vulgaris). Ardea 69:1-67.

Wetzel, A. N., and J. T. LeJeune. 2006. Clonal dissemination of Escherichia coli O157:H7 subtypes among dairy farms in northeast Ohio. Appl. Environ. Microbiol. 72:2621-2626. http://dx.doi. org/10.1128/AEM.72.4.2621-2626.2006. 